COLABORACIONES INTERNACIONALES CON TRADUCCIÓN 



\title{
LA PROTECCIÓN PENAL DE LA VIDA SILVESTRE: EL VALOR PROTEGIDO POR LA LEGISLACIÓN BRASILEÑA
}

\author{
Maria Auxiliadora MINAHIM \\ Lucas Gabriel COSTA
}

\begin{abstract}
Resumen:Lapreservación del medio ambiente como base esencial para el mantenimiento de la vida en todas sus manifestaciones requiere la sistematización de las formas de control con la capacidad para fortalecer las normas éticas de la conducta humana. Es a partir de esta comprensión que el presente estudio tiene como propuesta central examinar la protección de la Fauna a través del sistema jurídico penal. Lo que se busca es incidir y criticar el valor que establece el contenido y los motivos de la ley penal que justifican la creación de un núcleo prohibitivo del comportamiento para el desarrollo de un entorno de respeto a la diversidad de la vida como una perspectiva indispensable. A pesar del sesgo penal, que toma la trayectoria construida mediante la medición de la inserción del sistema penal como un instrumento de control, la crítica no revelará el conflicto presente en la relación entre el desarrollo técnico y de mercado, en vista de la importancia de proteger al medio ambiente, especialmente a la fauna. La consiguiente protección de un paradigma reforzado por una ideología que proyecta una ética de valoración en la relación de los humanos con los animales, como un parámetro a los convenios y programas de comportamiento en la sociedad contemporánea
\end{abstract}

Palabras clave: Control Social. Protección Penal. Protección de la Vida Silvestre.

Abstract:The preservation of the environment as an essential basis for the maintenance of life in all its manifestations requires systematization of the forms of control with the capacity to support the ethical norms of human behavior. It is from this understanding that the present study has as central proposal to examine the protection of the Fauna through the criminal legal system. What is sought is to influence and criticize the value established by the content and motives of the criminal law that justify the creation of a prohibitive core of behavior for the development of an environment of respect for the diversity of life as an indispensable perspective. In the face of the criminal bias, which takes the trajectory constructed by measuring the insertion of the criminal system as an instrument of control, the criticism will not reveal the present conflict in the relationship between technical and market development. Given the importance of Protect the environment, especially the fauna. The consequent protection of a paradigm reinforced by an ideology that projects an ethic of valuation in the relationship of humans with animals, as a parameter to the conventions and programs of behavior in contemporary society

\footnotetext{
* Doctora en Derecho Penal, Universidade Federal do Rio de Janeiro. Doctora en Derecho, Universidade Federal do Paraná. Professora Titular, Universidade Federal da Bahia, Brasil.

** Doctorando, Derecho, Universidade Federal da Bahia, Brasil.
} 
Key words: Social Control. Criminal Protection. Fauna.

\section{INTRODUÇÃO}

O meio ambiente, enquanto sistema formado pela comunhão de espécies, segue, tradicionalmente, no âmbito da valoração sócio-política de sua existência, uma dimensão antropocêntrica que influi nos métodos de controle voltados ao equilíbrio de sua unidade. No caminhar em que se desenvolve a dinâmica das sociedades ocidentais, a análise da adequação e da relação de coexistência entre espécies, entre o ser humano e a fauna, especialmente, compõe uma pauta fundamental que transversaliza, ou integra, as reflexões que, cientificamente, buscam caminhos ao desenvolvimento de um ambiente harmônico e justo.

Sob um viés ambientalista, isso representa evidenciar e problematizar a necessidade da construção de métodos de controle e programas de orientação a uma convenção comportamental capaz de majorar a importância da manutenção da integridade da vida. É aqui que se demonstra a relevância do direito penal, um sistema de controle institucionalizado, capaz de criar pautas comportamentais com o horizonte de expectativa ao desenvolvimento de uma sociedade constituída por uma ideologia que reforce a necessidade de respeito do homem com outras espécies.

A deferência à vida requer uma compreensão extensiva capaz direcionar o ser humano a um ideal de proteção e preservação de si e do meio ambiente. A racionalidade, tomada para distanciar valorativamente a existência do ser humano, e as circunstâncias que lhes são inerentes, dos outros seres vivos que compõem o meio ambiente, especialmente os animais, justificando, assim, uma hierarquização entre as espécies, não justifica uma relação utilitarista total que orienta o ser humano como um ser que detém o animal

\section{INTRODUCCIÓN}

El medio ambiente como un sistema formado por la comunidad de especies, sigue tradicionalmente, dentro de la evaluación socio-política de su existencia, una dimensión antropocéntrica que influye en los métodos de control destinadas a equilibrar su unidad. En el paseo que se desarrolla la dinámica de las sociedades occidentales, el análisis de la relación de adecuación y la convivencia entre las especies, entre seres humanos y animales, sobre todo, dispone una agenda fundamental que atraviesa, o parte, de las reflexiones que, científicamente, buscan maneras de desarrollar en un ambiente armonioso y justo.

El anhelo ecologista, establece evidencias que cuestionan la necesidad de construir mecanismos de control con programas de orientación capaces de generar que el comportamiento asuma interés en mantener la integridad de la vida. Es aquí donde se muestra la importancia del derecho penal, a través de un sistema de control institucional, capaz de crear pautas de comportamiento con el horizonte de perspectivas para el desarrollo de una sociedad con una ideología que refuerza la necesidad de respetar al hombre con otras especies.

El cuidado de la vida requiere una amplia comprensión que pueda dirigir al ser humano a un ideal de protección y preservación de uno mismo y del medio ambiente. La racionalidad, conlleva a distanciarse evaluativamente entre la existencia del hombre y los otros seres vivos que componen el medio ambiente, especialmente a los animales, lo que justifica una jerarquía entre las especies, sin embargo esta no justifica una relación utilitaria total, que guíe al ser humano como un ser que posee al animal como un objeto, 
como um objeto, uma coisa à sua completa e indiscriminada disposição.

É nesse contexto que se pretende discutir a necessidade e o fundamento da proteção penal dispensada à fauna, que revela em seu conteúdo o conflito inerente à relação existencial entre o ser humano e outras espécies de vida. Conflito que se materializa na crítica do olhar que se lança ao outro, seja como um ser importante em sua essência ou como relevante em sua existência na interação com o ser humano.

A questão que se expõe é o que orienta o homem no âmbito da proteção ao meio ambiente: o respeito à vida animal em si, enquanto respeito aos seres que coabitam um mesmo ambiente ou a fauna como um complexo de coisas disponíveis, a serem dominadas e utilizadas para satisfação do interesse humano. A proteção penal ao meio ambiente, assim, é um tema complexo que pode significar um cuidado da espécie humana consigo própria, bem como a construção de um novo perfil ideológico social, que exige uma compreensão e atenção sobre o desejo e seu movimento de apossamento sobre as coisas e os seres.

A questão que se quer introduzir contém uma dupla indagação: existe um real interesse de preservação da fauna, enquanto um valor em si próprio, de forma que as normas, por representarem as expectativas da sociedade, tenham vigência social ou, o que a lei busca, é criar, estimular ou fortalecer, na consciência social, a necessidade de preservação da vida?

A tutela penal da fauna é um desses temas que põem em evidência os conflitos com que se defronta o homem, colocado entre formas de desejo aparentemente opostas. A dualidade do ser humano e sua dificuldade na preservação do meio ambiente de onde afinal retira os recursos necessários para satisfação una cosa a su completa e indiscriminada disposición.

En este contexto, se propone discutir la necesidad y la base de la protección penal dada a la vida silvestre, que revela en su contenido el conflicto inherente a la relación existencial entre los seres humanos y otras especies vivas. El conflicto se materializa en mirada crítica que lanza al otro, ya sea como un ser importante en su esencia o como relevante en su existencia en la interacción con los seres humanos.

El asunto que se expone es lo que guía al hombre bajo la protección del medio ambiente: el respeto por la vida animal en sí, mientras que el respeto de los seres que cohabitan el mismo medio ambiente o los animales como un conjunto de cosas disponibles, que hay que dominar y utilizar para la satisfacción del interés humano. La protección penal del medio ambiente, es un tema complejo que puede significar un cuidado de la especie humana consigo misma, generando una construcción de un nuevo perfil social ideológico, que exige la comprensión y atención en el anhelo de adueñarse de las cosas y los seres.

El cuestionamiento que se quiere introducir contiene una doble pregunta: ¿Existe un verdadero interés para la conservación de fauna como un valor en sí mismo, ya que lo que las normas representan son las expectativas de la sociedad, tiene validez social, o lo que la ley busca es crear, estimular y fortalecer la conciencia social, la necesidad de preservación de la vida?

La protección penal de la vida silvestre es uno de esos temas que ponen de relieve los conflictos que enfrenta el hombre, que lo posicionan entre las formas de deseo aparentemente opuesto. La dualidad del ser humano dificulta la preservación del medio ambiente, se ve afectada, ya que este requiere recursos necesarios para satisfacer sus nece- 
de suas necessidades se expõem, com menos disfarces, na relação com os animais.

De tal forma é complexa esta relação que talvez seja possível afirmar que o direito, que permite o abate do boi, quer que a mão do homem proteja o sabiá. É que, de fato, à luz dos princípios ambientalistas se percebe, com facilidade, muitas das incoerências do homem contemporâneo na preservação da natureza, já que, nessa missão, ele vive um conflito: de um lado deseja preservar o ambiente, de outro, quer o próprio bem estar e de sua espécie, ainda que, para isso, o planeta seja cada vez mais espoliado.

\section{A CONFLituAlidAdE NA ESFERA DE PROTEÇÃO AO MEIO AMBIENTE}

Já se observou, a propósito dos movimentos ecológicos que, se a proteção à natureza contra a destruição demandasse apenas sua expressão em slogans, haveria uma adesão geral. Como se trata de escolhas reais, porém, os problemas se multiplicam, já que não se pode pedir, ao mesmo tempo, a interdição de usinas elétricas atômicas e energia mais barata. Se se deseja, realmente, dispensar uma tutela efetiva ao meio ambiente, a sociedade deve estar pronta para querer menos do que tem, se isto for necessário, abrindo mão do que produz com vistas apenas a usufruir de comodidades supérfluas.

Aqui é possível encontrar outra grande contradição do homem contemporâneo: querer resultados para cuja consecução não tenha que contribuir. Ou seja, desejam-se soluções mágicas para uma vida sempre materialmente próspera sem que isso possa implicar em restrições de qualquer natureza.

Autores debitam essas contradições a causas sócio-políticas. Wolf Paul diz que o grande problema do direito ambiental reside na conflitualidade. Afirma o autor que, ao mesmo tempo em que se deve responder às pressões sociais pela melhoria da qualidade de vida e diminuição de risco, deve-se, tam- sidades y esto lo expone a un enfrentamiento en su relación con los animales.

Tan compleja es esta relación que puede ser posible decir que la ley, que permite que la masacre de ganado, sea cual sea la mano del hombre que la realice, es, de hecho, a la luz de los principios ambientales, inconsistente. Se puede percibir con facilidad muchas de esas inconsistencias del hombre contemporáneo en la preservación de la naturaleza, ya que en esa misión se vive un conflicto: por un lado, para preservar el medio ambiente, por el otro, el bienestar del mismo y de su especie, incluso para eso, el planteamiento se desnuda cada vez.

EL CONFLICTO EN EL ÁMBITO DE PROTECCIÓN DEL MEDIO AMBIENTE

Ya se ha señalado, el propósito de los movimientos ecológicos, si la protección de la naturaleza solo requiriese una consigna, un slogan, se tendría una adhesión general. Como se trata de opciones reales, sin embargo, los problemas se multiplican, ya que no se puede pedir al mismo tiempo, la prohibición de las plantas de energía nuclear y energía más barata. Si se quiere hacer efectiva una verdadera protección eficaz del medio ambiente, la sociedad debe estar preparada para recibir menos de lo que tiene, si fuera necesario se tendría que renunciar a lo que se produce actualmente y simplemente vivir con lo que es superfluo, es decir lo que resta al final.

Aquí se puede encontrar otra gran contradicción del hombre moderno: obtener resultados sin poder intervenir en la obtención de los mismos. Es decir, anhelando soluciones mágicas para una vida siempre próspera materialmente, sin que impliquen restricciones de cualquier tipo.

Autores imputan tales contradicciones a las causas socio-políticas. Wolf Paulo dice que el principal problema de la legislación ambiental radica en el conflicto. El autor afirma que, al mismo tiempo en el que se debe responder a las presiones sociales mediante la mejora de la calidad de vida y la 
bém favorecer o processo de acumulação sem tornar mais gravosas as condições do mercado1. Não é de estranhar, portanto, que, apesar da crescente proteção jurídica do meio ambiente, ele continue sendo degradado de forma alarmante.

A justificação da proteção penal no Brasil se apoia no discurso eloquente do legislador constitucional no artigo 225: Todos têm direito ao meio ambiente ecologicamente equilibrado, bem de uso comum do povo e essencial à sadia qualidade de vida, impondo-se ao Poder Público e à coletividade o dever de defendê-lo e preservá-lo para as presentes e futuras gerações. ${ }^{2}$ Discurso que não corresponde à história da humanidade ou talvez signifique um conflito entre seus valores e necessidades.

O homem, que abate o boi, não só põe cravos nos cavalos para que cavalguem mais rápido, marca as ovelhas para que não sejam roubadas e tira-lhe a lã para se abrigar do frio; também testa produtos de maquilagem cegando coelhos, mata espécies para aprender mais sobre a vida e aprisiona as aves para ouvir seu canto.

O homem, aliás, abate ao próprio homem e desfaz seus corpos em pedaços, comemorando o êxito na ação de aniquilamento do inimigo. Talvez destrua mais do que qualquer fera, motivando Saramago a afirmar que: De algo sempre haveremos de morrer, mas já se perdeu a conta aos seres humanos

\footnotetext{
1 WOLF, Paul. Magacriminalidad ecológica e derecho ambiental simbólico (una intervención iusfilosófica en el sistema de la organizada irresponsabilidad): Barcelona, 1990,ejemplar dactilografado.

2 BRASIL. Constituição Federal. Presidência da República, Casa Civil, Subchefia para Assuntos Jurídicos. Disponível em: http://www.planalto.gov. br/ccivil_03/constituicao/constituicaocompilado. htm. Acesso em 29 de out de 2016.
}

reducción del riesgo, también se debería favorecer el proceso de acumulación sin hacer que las condiciones de mercado ${ }^{1}$ sean más graves. No es de extrañar, pues, que, a pesar del aumento de la protección jurídica del medio ambiente, se continúa degradando a un ritmo alarmante.

La justificación de la protección penal en Brasil está basado en el discurso elocuente del legislador constitucional en el artículo 225: Toda persona tiene derecho a un medio ambiente ecológicamente equilibrado $y$ de uso común y esencial para una calidad de vida saludable, imponiendo al Gobierno y a la colectividad la obligación de defenderla y preservarla para las generaciones presentes $y$ futuras. ${ }^{2}$ Discurso que no coincide con la historia de la humanidad o puede significar un conflicto entre sus valores y necesidades.

El hombre, que mata al buey, no sólo pone clavos en los caballos para cabalgar más rápido, marca a las ovejas para que no se robadas y se lleva la lana para protegerse del frío; también pone a prueba los productos de maquillaje que causan ceguera en los conejos, mata especies para aprender más sobre la vida y encarcela a los pájaros para escuchar su canto.

El hombre, de hecho, mata al propio hombre, deshace su cuerpo en pedazos, y celebra con éxito la aniquilación del enemigo. Tal vez destruya más que cualquier otro animal, aspecto que motiva a Saramago a decir que: De algo siempre vamos a morir, pero se ha perdido la cuenta de las personas que murie-

\footnotetext{
${ }^{1}$ WOLF, Paul. Magacriminalidad ecológica e derecho ambiental simbólico (una intervención iusfilosófica en el sistema de la organizada irresponsabilidad): Barcelona, 1990,ejemplar dactilografado.

2 BRASIL. Constituição Federal. Presidência da República, Casa Civil, Subchefia para Assuntos Jurídicos. Disponible en: http://www.planalto.gov. br/ccivil_03/constituicao/constituicaocompilado. htm. Aceso em 29 de oct de 2016.
} 
mortos das piores maneiras que seres humanos foram capazes de inventar. ${ }^{3}$

Quanto aos animais, disse Claude Bernard, não parece ter qualquer dúvida quanto ao papel puramente utilitário que eles têm na vida dos humanos, temos o direito, total e absoluto, de fazer experimentos e vivissecção. Coerente com sua visão utilitarista, o autor observava que seria estranho se fosse reconhecido o direito de usar os animais para serviços caseiros e alimentação e, ao mesmo tempo, fosse proibido seu uso para o ensino da medicina. ${ }^{4}$ Dessa forma, entendia que nenhuma experimentação em humanos deveria ser feita sem ser precedida por testes em cães.

Menelick de Carvalho afirma que o ideal de todo Direito é que ele seja cumprido porque as pessoas acreditam na bondade de suas normas e não por medo da polícia e da prisão. ${ }^{5}$ Outros autores ao reafirmar a distinção das esferas ética, jurídica, política e religiosa, como forma de reassegurar as liberdades, dizem que a lei não transforma as pessoas em seres éticos e, assim, as normas jurídicas não podem cumprir essa função.

\section{A PROTEÇÃo DA FAUna ATRAVÉS DA PROIBIÇÃO PENAL}

Considerando que o Direito empresta densidade à moral moderna que, por seu turno, lhe dá legitimidade, pode-se compreender porque o direito penal quer colaborar para a instalação de uma sociedade ética na qual se

\footnotetext{
3 SARAMAGO, José. O Fator Deus. Fonte: Folha de S. Paulo, 16.09.o1. Disponível em: www1.folha.uol. com.br/folha/mundo/ult94u29519.shtml. Acesso em: 25 dez 2015.

4 GOLDIM, José Roberto e Márcia Mocellin Raymundo. Pesquisa em Saúde e Direito dos Animais. 1999. www.ufrgs.br/HCPA/animrt.ht

5 CARVALHO NETO, Menelick. Notas de Aulas: curso de Hermenêutica Filosófica e Teoria da Interpretação, Mestrado em Direito, Faculdade de Direito da UFBa., Salvador, 2000.
}

ron en los peores maneras que los humanos eran capaces de inventar". ${ }^{3}$

En cuanto a los animales, dijo Claude Bernard, sin parecer tener alguna duda sobre el papel puramente utilitario que desempeñan en la vida de los seres humanos, tenemos el derecho, total y absoluto, para hacer experimentos y disecciones. Consistente con su punto de vista utilitario, el autor señaló además que sería extraño si se concede el derecho de utilizar animales para los servicios domésticos y alimentos y, al mismo tiempo, prohibir su uso para la educación médica. ${ }^{4}$ Por lo tanto, entiende que ningún experimento con seres humanos debe ser llevado a cabo sin ser precedida de pruebas en perros.

Menelick de Carvalho asevera que el ideal de toda ley es que sea cumplida porque la gente cree en la bondad de sus reglas y no por miedo a la policía y la prisión. ${ }^{5}$ Otros autores, al reafirmar la distinción de las esferas éticas, legales, políticas y religiosas, con el fin de asegurar a las libertades, dicen que la ley no transforma a las personas en seres éticos y por lo tanto el marco legal no puede cumplir esta función.

\section{LA PROTECCIÓN DE LA VIDA SILVESTRE MEDIANTE LA PROHIBICIÓN PENAL}

Mientras el Derecho le brinda consistencia a la moral moderna, que, a su vez, le da legitimidad, se puede entender por qué la ley penal colabora para la instalación de una sociedad ética para desarrollar las relaciones

\footnotetext{
${ }^{3}$ SARAMAGO, José. O Fator Deus. Fonte: Folha de S. Paulo, 16.09.01. Disponible en: wwwl.folha.uol. com.br/folha/mundo/ult94u29519.shtml. Aceso en: 25.12. 2015

4 GOLDIM, José Roberto y Márcia Mocellin Raymundo. Pesquisa em Saúde e Direito dos Animais. 1999. www.ufrgs.br/HCPA/animrt.ht

5 CARVAlHO NETO, Menelick. Notas de Aulas: curso de Hermenêutica Filosófica e Teoria da Interpretação, Mestrado em Direito, Faculdade de Direito da UFBa., Salvador, Brasil, 2000.
} 
desenvolvam as relações do homem com os seres com os quais partilha a vida.

Na busca desse sentido no âmbito do direito ambiental, o ordenamento jurídico brasileiro dispõe de leis que têm como objeto material a fauna. A Lei $\mathrm{n}^{\circ} 11.794$, de 8 de outubro de 2008 , embora com críticas pertinentes, regulamenta a prática didáticocientífica da Vivissecção de Animais, a Lei 9605/98 estabelece os Crimes Ambientais, que reuniu grande parte dos delitos nesta área, facilitando a sistematização da matéria (além de outras esparsas de proteção à fauna como Lei $n^{\circ} 5.197$, de 3 de janeiro de 1967 , por exemplo).

Discute-se, ${ }^{6}$ ainda, a vigência ou não da que proíbe a pesca ou qualquer forma de molestamento intencional, de cetáceos em águas jurisdicionais brasileiras, admitindo-se sua permanência no ordenamento jurídico porque não foi prevista na lei 9605 a previsão de tal conduta.

Embora se possa criticar o fato de alguns tipos afrontarem princípios básicos do direito penal liberal, ${ }^{7}$ seja por não haver taxatividade, ${ }^{8}$ como ocorre com o art. 32 da

\footnotetext{
${ }^{6}$ PRADO, Luis Régis. Crimes contra o ambiente: anotações à lei 9605. 2a . Ed. São Paulo: RT, 2001.

7 Una buena parte de las ideas y valores que siguen procurando algún ponto de humanidad y civilización a nuestro mundo contemporáneo, por más que tuvieran un origen más antiguo, se forjaron precisamente em siglo XVIII: los derechos humanos, el constitucionalismo, la democracia política y el gobierno representativo, el cosmopolitismo, incluso la solidariedad cuyo precedente bien puede rastrearse em la venerable filantropia $y$, desde luego, también el garantismo penal, que representa la más fecunda a nuestros días de la filosofia jurídica ilustrada. La Ilustración: De uma filosofia Especulativa a uma Filosofia para a ação. O Problema Penal. IN: História dos Direitos Fundamentais P.132.

8 A taxatividade decorre do princípio da legalidade em âmbito penal, estabelecendo um mandado de determinação capaz de orientar um perfeito juízo de adequação, subsunção, entre a conduta do agente e o comportamento proibido pela norma penal. Para Santiago Mir Puig "el postulado de precisión de la ley da lugar al llamado «mandato de determinación», que exige que la ley determine de forma su-
}

del hombre con los seres con los que compartimos la vida.

En la búsqueda de este significado en el derecho ambiental, el ordenamiento jurídico brasileño tiene leyes que exponen como objeto material a la vida silvestre. La Ley $\mathrm{n}^{\circ}$ 11.794, del 8 de octubre de 2008 , si bien con la crítica relevante, regula la práctica científica didáctica de las disecciones de animales, la Ley 9605/98 establece la delitos ambientales, que reunió a la mayor parte de los delitos en esta zona, lo que facilita la sistematización de la materia (y otra protección a la fauna escasa como la Ley No 5.197, de 3 de enero de 1967, por ejemplo).

Se discute ${ }^{6}$ también la presencia o ausencia de la ley 76431987 , que prohíbe la pesca o cualquier forma de acoso intencional de cetáceos en aguas brasileñas, asumiendo su permanencia en el sistema legal, ya que no estaba prevista la conducta por la ley 9605.

Aunque se puede criticar el hecho de que algunos tipos confrontan principios básicos del derecho penal liberal ${ }^{7}$ sea porque no hay ninguna taxatividad, ${ }^{8}$ como ocurre con el

\footnotetext{
${ }^{6}$ PRADO, Luis Régis. Crimes contra o ambiente: anotações à lei 9605. 2a . Ed. São Paulo: RT, Brasil, 2001.

7 Una buena parte de las ideas y valores que siguen procurando algún ponto de humanidad y civilización a nuestro mundo contemporáneo, por más que tuvieran un origen más antiguo, se forjaron precisamente en el siglo XVIII: los derechos humanos, el constitucionalismo, la democracia política y el gobierno representativo, el cosmopolitismo, incluso la solidaridad cuyo precedente bien puede rastrearse en la venerable filantropía y, desde luego, también el garantismo penal, que representa la más fecunda a nuestros días de la filosofía jurídica ilustrada. La Ilustración: De uma filosofia Especulativa a uma Filosofia para a ação. O Problema Penal. IN: História dos Direitos Fundamentais, p.132.
}

8 A taxatividade decorre do princípio da legalidade em âmbito penal, estabelecendo um mandado de determinação capaz de orientar um perfeito juízo de adequação, subsunção, entre a conduta do agente e o comportamento proibido pela norma penal. Para Santiago Mir Puig "el postulado de precisión de la ley da lugar al llamado «mandato de determinación», que exige que la ley determine de forma suficientemente diferenciada las distintas conductas 
Lei 96059, seja por quebra do princípio da proporcionalidade ou mesmo da razoabilidade (apenas para dar a impressão de um Estado presente e atento), o fato é que há previsões legislativas para condutas que lesem ou ponham sob-risco de lesão o meio ambiente e a fauna que nele vive.

A criminalização decorrente da Lei 9605 de 1998, especialmente, possui apoio numa base cultural vinculada a um viés ideológico ambientalista, que segue o mandado implícito de criminalização presente na ordem constitucional instituída em 1988. Nesse sentido, o comportamento de ataque à vida ou integridade física do animal, na sociedade contemporânea, passa a representar uma conduta de maior reprovação e censura social, ao mesmo tempo em que se constitui como instrumento que garante proteção ao perfil ideológico que decorre da norma instituída no artigo 225, inciso VII, da Constituição Federal. ${ }^{10}$

Entre o direito penal mínimo que se recusa a intervir em conflitos que podem ser

ficientemente diferenciada las distintas conductas punibles y las penas que pueden acarrear. Constituye éste un aspecto material del principio de legalidad que trata de evitar la burla del significado de seguridad y garantía de dicho principio, burla que tendría lugar si la ley penal previa se limitase a utilizar cláusulas generales absolutamente indeterminadas.” MIR PUIG, Santiago. Bases Constitucionales del Derecho Penal. Iustel: Madrid, 2011. P. 74.

9 O artigo 32, caput, pune, com pena de detenção de três meses a um ano, a conduta daquele que praticar ato de abuso, maus tratos, ferir ou mutilar animais silvestres, domésticos ou domesticados, nativos ou exóticos. Grifo da autora.

${ }^{10}$ Art. 225. Todos têm direito ao meio ambiente ecologicamente equilibrado, bem de uso comum do povo e essencial à sadia qualidade de vida, impondo-se ao Poder Público e à coletividade o dever de defendê-lo e preservá- lo para as presentes e futuras gerações. [...] VII - proteger a fauna e a flora, vedadas, na forma da lei, as práticas que coloquem em risco sua função ecológica, provoquem a extinção de espécies ou submetam os animais a crueldade. IN: BRASIL. Constituição Federal. Presidência da República, Casa Civil, Subchefia para Assuntos Jurídicos. Disponível em: http://www.planalto.gov.br/ccivil_03/ art. 32 de la Ley 9605, ${ }^{9}$ ya sea por incumplimiento del principio de proporcionalidad o razonabilidad y esto sólo para dar la impresión de un estado presente y atento, el hecho es que hay previsiones legales para conductas que lesionan o ponen en riesgo de daño al medio ambiente y la fauna que vive en ella.

La penalización derivada de la Ley 9605 de 1998, en particular, ha apoyado una base cultural vinculado a un sesgo ideológico ecologista, que sigue el mandato implícito de esta penalización en el orden constitucional establecido en 1988. En este sentido, el comportamiento de ataque a la vida o la integridad física del animal, en la sociedad contemporánea, viene a representar un curso de mayor desaprobación y rechazo social, si bien es un instrumento que proporciona protección al perfil ideológico que sigue la regla establecida en el artículo 225, inciso VII, de la Constitución Federal. ${ }^{10}$

Entre el derecho penal mínimo, que se niega a intervenir en los conflictos que pue-

punibles y las penas que pueden acarrear. Constituye éste un aspecto material del principio de legalidad que trata de evitar la burla del significado de seguridad y garantía de dicho principio, burla que tendría lugar si la ley penal previa se limitase a utilizar cláusulas generales absolutamente indeterminadas.” MIR PUIG, Santiago. Bases Constitucionales del Derecho Penal. Iustel: Madrid, 2011. P. 74.

9 "O artigo 32, caput, pune, com pena de detenção de três meses a um ano, a conduta daquele que praticar ato de abuso, maus tratos, ferir ou mutilar animais silvestres, domésticos ou domesticados, nativos ou exóticos." Grifo de la autora.

${ }^{10}$ Art. 225. Todos têm direito ao meio ambiente ecologicamente equilibrado, bem de uso comum do povo e essencial à sadia qualidade de vida, impondo-se ao Poder Público e à coletividade o dever de defendê-lo e preservá- lo para as presentes e futuras gerações. [...] VII - proteger a fauna e a flora, vedadas, na forma da lei, as práticas que coloquem em risco sua função ecológica, provoquem a extinção de espécies ou submetam os animais a crueldade. IN: BRASIL. Constituição Federal. Presidência da República, Casa Civil, Subchefia para Assuntos Jurídicos. Disponible en: http://www.planalto.gov.br/ccivil_03/ constituicao/constituicaocompilado.htm. Aceso em 29 de oct de 2016 
pacificados por outros ramos do direito e que, ademais, não impõem a dor da pena, e a necessidade de atender a temores coletivos (reais ou imaginários) as normas penais têm sido alvo de críticas incisivas e continuas, sobretudo por parte de penalistas da escola de Frankfurt.

$\mathrm{Na}$ esteira de Hassemer, afirma-se que o Direito Penal não tem aptidão nem foi predestinado a tratar dos bens jurídicos transindividuais. Esta tarefa caberia ao chamado Direito de Intervenção, por ele proposto: um Direito menos garantístico em termos materiais e processuais e com sanções menos severas do que as existentes no Direito Penal tradicional. Insistindo nessa missão, faria um mergulho do Direito Penal nas turbulentas águas do risco, tal como Paulo Silva Fernandes refere-se à situação, o que afetaria suas matrizes na medida em que romperia $\mathrm{cm}$ diversas de suas teses centrais, entre as quais a da exclusiva proteção de bens jurídicos determinados, a da intervenção mínima e a da necessidade. Em contrapartida, dar-se-ia uma expansão das leis simbólicas, com o recurso abusivo à criminalização de condutas de perigo abstrato, às normas penais em branco e à criação de bens jurídicos destituídos de substancialidade.

$\mathrm{O}$ ambientalismo e o animalismo, assim como o chamado novo constitucionalismo latino americano, todavia pressionam no sentido de estender a proteção jurídico-penal da vida a outras espécies além da humana.

O direito penal vive assim, como se afirmou, influencias, por vezes, contraditórias quando tutela a fauna, mas esta contradição é o reflexo da relação complexa e conflituosa do homem com a natureza.

Rumos contraditórios de uma relação complexa e conflituosa que se demonstra no fundamento posto a justificar a tutela penal do meio ambiente, especialmente da fauna.

constituicao/constituicaocompilado.htm. Acesso em 29 de out de 2016. den ser pacificados por otras ramas del derecho y, por otra parte, que no impone la pena de castigo, y la necesidad de abordar las preocupaciones colectivas (reales o imaginarias), las leyes penales han sido objeto de crítica insensibles y continuas, sobre todo por los criminalistas de la escuela de Frankfurt.

Como consecuencia de lo afirmado por Hassemer, se establece que el derecho penal no tiene ninguna aptitud ni estaba predestinado para hacer frente a los bienes. Esta tarea sería llevada a cabo por el Derecho de Intervención, se propone: un Derecho menos garantista en términos sustantivos y de procedimiento y con penas menos severas que las de la ley penal tradicional. En una inmersión en el derecho penal en las turbulentas aguas del riesgo se insistirá en esta misión, como Paulo Silva Fernandes se refiere a la situación, exponiendo se afectaría la matriz de sus tesis en la medida que se estas sufrirían un quiebre que se vería reflejado en la noción de protección exclusiva de ciertos intereses legales, la intervención mínima y la necesidad. Por otro lado, daría lugar a una expansión de las leyes simbólicas, con el abuso de la penalización del peligro abstracto de conductas, las normas penales en blanco y creación de bienes legales carentes de sustancialidad.

Ambientalismo y la animalidad, así como el llamado nuevo constitucionalismo latinoamericano, presionan en el sentido de ampliar la protección jurídico penal de la vida de la mayor cantidad de especies además de la humana.

El derecho penal vive algunas veces, como se afirmó, influencias contradictorias cuando se ocupa de la vida silvestre, pero estas contradicciones son el reflejo de una relación compleja entre el humano con la naturaleza.

En el fundamento de la protección penal del medio ambiente existen rumbos contradictorios que derivan en una relación compleja y conflictiva, especialmente con la fauna. Hay tendencias que proponen a la fauna 
Existem construções que propõem a fauna como bem associado ao ser humano, como bem coletivo ou inerente aos direitos humanos, sendo necessário para proteção da vida humana e ao desenvolvimento a gerações futuras. ${ }^{11}$ Adequado é sustentar que a fauna integra o meio ambiente, que se dispõe como bem jurídico a ser tutelado pela norma penal. Não se desprestigia a necessidade de considerar a proteção do meio ambiente em prol do ser humano, mas tal proteção não deve tornar invisível a diversidade da vida que compõe tal meio, que possui essência para além da existência humana, merecendo respeito e proteção.

Por isso, nas infrações faunísticas, o bem jurídico protegido é o ambiente, de acordo com o direito penal tradicional; a tutela da fauna é subsidiária e integra a lei na medida em que se trata de um dos elementos que compõem o bem jurídico ambiental. ${ }^{12}$ Tratar a fauna como elemento do bem jurídico, no entanto, torna-se sensível quando se propugna para os animais a qualidade de sujeito e direitos.

Novos argumentos e fatos parecem por em questão a existência de um atributo exclusivo do ser humano, fragilizando a ideia de que existe uma rígida linha demarcatória entre o homem e os demais animais, sugerindo que sua distinção é muito mais de grau

\footnotetext{
${ }^{11}$ ZAFFARONI, Eugenio Raúl. «La naturaleza como persona: Pachamama y Gaia». En Bolivia: Nueva Constitución Política del Estado. Conceptos elementales para su desarrollo normativo, 109-132. La Paz: Vicepresidencia del Estado Plurinacional de Bolivia, 2010.

${ }^{12}$ Para Luiz Régis Prado, o objeto da conduta exaure o seu papel no plano estrutural; do tipo, é elemento do fato. Já o bem jurídico se evidencia no plano axiológico, isto é, representa o peculiar ente social de tutela normativa penal. Não são conceitos independentes um do outro, mas que se inter-relacionam, numa mútua imbricação. PRADO, Luiz Regis. Bem jurí-

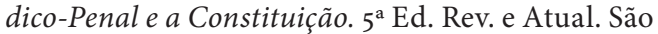
Paulo: Editora Revista dos Tribunais, 2011. P. 51.
}

como bien asociado al ser humano, como bien colectivo e inherente a los derechos humanos, siendo necesario para proteger la vida humana y el desarrollo de las generaciones futuras. ${ }^{11}$ Conviene manifestar que la fauna integra el medio ambiente, que además ofrece un bien jurídico a ser protegido por la norma. Es necesario no desprestigiar la necesidad de considerar la protección del medio ambiente a favor de los seres humanos, pero tal protección no debe convertir en invisible a la diversidad de vida que constituye un medio, de tal manera que tiene esencia, más allá de la existencia humana, merece respeto y protección.

Por lo tanto, en los delitos contra la fauna, el bien jurídico protegido es el medio ambiente, de acuerdo con la ley penal tradicional; la protección de la fauna es subsidiaria e integra a la ley en la medida en que se trata de uno de los elementos que componen el bien jurídico ambiental. ${ }^{12}$ El tratamiento de los animales, como un bien jurídico a ser tutelado, se convierte sensible cuando se propugna la cualidad de los animales como sujetos de derechos.

Nuevos argumentos y hechos ponen en tela de juicio la existencia de un único atributo del ser humano, lo que debilita la idea de que hay una línea rígida entre el hombre y otros animales, lo que sugiere que la distin-

\footnotetext{
${ }^{11}$ ZAFFARONI, Eugenio Raúl. «La naturaleza como persona: Pachamama y Gaia». En Bolivia: Nueva Constitución Política del Estado. Conceptos elementales para su desarrollo normativo, 109-132. La Paz: Vicepresidencia del Estado Plurinacional de Bolivia, 2010.

${ }^{12}$ Para Luiz Régis Prado, o objeto da conduta exaure o seu papel no plano estrutural; do tipo, é elemento do fato. Já o bem jurídico se evidencia no plano axiológico, isto é, representa o peculiar ente social de tutela normativa penal. Não são conceitos independentes um do outro, mas que se inter-relacionam, numa mútua imbricação. PRADO, Luiz Regis. Bem jurídico-Penal e

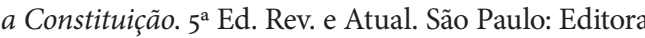
Revista dos Tribunais, Brasil, 2011. P. 51.
} 
ou de complexidade do que de essência, ${ }^{13}$ como se tem divulgado.

Tem-se alertado que, apesar de, nos últimos séculos, ter-se postulado por direitos iguais entre todos os humanos, são poucos os direitos reconhecidos aos animais. No entanto, sendo dotados de cérebro e de sistema nervoso eles são capazes, como os homens, de sentir dor. A dor carece de caracterização por espécie, ela provoca sofrimento quer se manifeste em um homem, um elefante ou um gato e, é esta capacidade de sentir uma sensação penosa, produzida pela excitação de terminações nervosas, que habilita os filósofos a falar em um direito dos animais a não sofrer. Assim, os militantes dos movimentos de liberação animal entendem que evitar o sofrimento constitui uma etapa na conquista de suas metas definitivas.

A lei 9605, no artigo 32 caput e seu parágrafo, proíbe, exatamente, as ações que possam causar sofrimento aos animais, o que pode revelar a imprecisão do bem jurídico tutelado pela norma. Se todos os tipos contidos na Lei de Crimes Ambientais têm como finalidade a proteção do meio ambiente, há que se indagar em que medida a crueldade contra um animal doméstico, por exemplo, afeta esse bem jurídico, objetivamente. Tudo levar a crer que a falta de coragem em avançar na formulação correta do valor protegido tenha inibido o legislador e doutrinadores a admitir, como bem jurídico protegido, como chegam a sugerir $\mathrm{Greco}^{14} \mathrm{e}$ José Duarte, ${ }^{15}$ o sentimento de solidariedade do homem com outros animais superiores.

Roxin, referido pelo primeiro autor, autor, prefere acreditar que este delito não protege

\footnotetext{
${ }^{13}$ GARCIA Fabric. ,De l'homme et de l'animal : différences de degré, de nature ou d'orientation? Em: Hominidées. Disponível emhttp://www.hominides.com/ html/references/de-l-homme-et-de-l-animal-mensonge-tromperie.php. Acesso em 1 dez. 2015.

14 GRECO, Luis - Princípio da ofensividade e Crimes de perigo abstrato, op. cit. p. 104.

15 Este, mais especificamente, com relação aos animais domésticos. DUARTE, José, Comentários à lei
}

ción es mucho más de grado o complejidad, no de esencia, ${ }^{13}$ como se ha descrito.

Se ha advertido que, a pesar que en los últimos tiempos se hayan postulado derechos iguales entre todos los seres humanos, aun son pocos los derechos reconocidos a los animales. A pesar de que estos se encuentren dotados de cerebro y del sistema nervioso, ellos son capaces como los humanos de sentir. El dolor carece de caracterización en las especies, pero se debe considerar que este causa sufrimiento, sea un hombre, un elefante o un gato, esta capacidad de sentir una sensación de dolor producido por la excitación de las terminaciones nerviosas, permite que los filósofos se pronuncien sobre la necesidad de un derecho para que los animales no sufran. Por lo tanto, los militantes de los movimientos de liberación de los animales entienden que para evitar el sufrimiento es un paso en la consecución de sus objetivos finales.

La Ley 9605, artículo 32, caput, y su párrafo prohíbe exactamente las acciones que causan sufrimiento a los animales, que podrían revelar la inexactitud del interés jurídico protegido por la norma. Si todos los tipos contenidos en la Ley de Delitos Ambientales están destinadas a proteger el medio ambiente, hay que preguntarse hasta qué punto la crueldad a un animal doméstico, por ejemplo, afecta este derecho legal, de manera objetiva. Todos llevan a creer que la falta de coraje para seguir en la formulación correcta del valor protegido ha inhibido la legislatura y estudiosos que admitir, así como bien jurídico protegido, ya que incluso sugieren

\footnotetext{
${ }^{13}$ GARCIA Fabric, De l'homme et de l'animal: différences de degré, de nature ou d'orientation? En: Hominidées. Disponible en http://www.hominides. $\mathrm{com} / \mathrm{html} / \mathrm{references} / \mathrm{de}-1$-homme-et-de-1-animalmensonge-tromperie.php. Aceso en 1 dec. 2015.
} 
a um bem jurídico específico, tratando-se de uma rara exceção de incriminação sem bem jurídico. Essa solução não desconhece a existência de valor a ser preservado, situando-se a meio caminho, quem sabe, entre considerar o animal um mero elemento do meio ambiente ou outorgar-lhe outra categoria jurídica. Pode-se afirmar, enfim, apesar da perspectiva antropocêntrica a partir da qual surgem as normas, que já é possível perceber nelas, latente, o reconhecimento de um valor intrínseco aos animais.

Tomando essa interpretação como definitiva, seria possível introduzir-se nova indagação: Por que, na lei de crimes ambientais, dentre as infrações ditas faunísticas, (art.32, caput e parágrafo $1^{\circ}$ ) são incriminadas as condutas de: praticar ato de abuso, maus tratos, ferir ou mutilar animais silvestres, domésticos ou domesticados, nativos ou exóticos, e, ainda, a de realizar experiência dolorosa ou cruel em animal vivo, ainda que para fins didáticos ou científicos, quando existirem recursos alternativos?

Uma leitura atenciosa dos dispositivos, com destaque para as expressões: maus tratos, ato de abuso, experiência dolorosa proporciona argumentos para reflexão em torno de hipótese de que a prática de crueldade deve ter sua compreensão obtida através da consideração da conduta humana que se reveste de maior reprovação na relação com os animais, mas na consideração do animal como um ser sensível.

A análise dos núcleos contidos no artigo 32 da Lei de Crimes Ambientais requer a uma compreensão do animal não como uma coisa, um objeto de livre disposição, mas como um ser vivo e sensível. Necessário, assim, ao ser humano, reconhecer um valor intrínseco nos seres dessa espécie e estender à integridade deste o ideal de proteção que se teve até então como exclusivamente humano, especificamente, a não sofrer lesões

das Contravenções Penais. Parte especial. 2 ed. Rio de Janeiro: Forense, 1958, p.315.
Greco $^{14}$ y José Duarte, ${ }^{15}$ que el sentimiento de solidaridad del hombre es superior al de los animales.

Roxin, mencionado por el primer autor, prefiere creer que este crimen no protege un bien jurídico específico, ya que es una rara excepción la incriminación sin bien jurídico. Esta solución no ignora la existencia de valor que se conserva, de pie a mitad de camino, tal vez, entre considerar al animal un elemento del medio ambiente o le conceda otra categoría legal. Se puede decir, por último, a pesar de la perspectiva antropocéntrica de los que proceden las reglas, que ya es posible verlos, latente, el reconocimiento de un valor intrínseco a los animales.

Tomando esta interpretación como definitiva, podría ser introducido a una nueva pregunta: ¿Por qué, en la ley de delitos ambientales, entre dichos delitos de fauna (Art.32, capítulo y el párrafo 1) son incriminados las conductas de: realizar un acto de abuso, malos tratos, herir o mutilar a los animales salvajes, domésticos o no domesticados, nativos o exóticos, y también para llevar a cabo experimentos dolorosos o crueles con animales vivos, incluso para fines educativos o científicos, cuando hay recursos alternativos?

Una lectura atenta de los dispositivos, especialmente las expresiones: malos maltratos, el acto de abuso, la experiencia dolorosa, proporciona argumentos para la reflexión en el supuesto de que la práctica de la crueldad debe haber obtenido su comprensión a través de la consideración de la conducta humana, que es de mayor fracaso en relación

\footnotetext{
${ }^{14}$ GRECO, Luis, Princípio da lesividade e crimes de perigo abstrato, ou algumas dúvidas diante de tantas certezas. Revista Brasileira de Ciências Criminais. São Paulo: RT,n. 49. P. 104, Brasil.

15 "Este, mais especificamente, com relação aos animais domésticos.” DUARTE, José, “Comentários à lei das Contravenções Penais.” Parte especial. 2 ed. Rio de Janeiro: Forense, 1958, p.315, Brasil.
} 
desnecessárias. Cleopas Santos ${ }^{16}$ acrescenta um argumento de natureza dogmática para reforçar a nova compreensão postulada. $\mathrm{O}$ autor afirma que a agravação da pena no caso de morte do animal resultante de maus tratos ou crueldade experimental (artigo 32, $2^{\circ}$, da Lei 9605) revela uma preocupação do legislador com o desvalor do resultado que, resulta, sem dúvida, do entendimento que o direito à vida e à integridade física são titularizados pelos animais.

\section{FUNDAMENTOS DA TUTELA PENAL DA} FAUNA

A deteriorização crescente do meio natural passou, porém desde algum tempo, a ser facilmente constatável, deixando de funcionar como mero aviso apocalíptico e mauagorento, interferindo diretamente na qualidade de vida das pessoas. Mesmo a população menos instruída (e também a parcela mais consumista) passou a tomar alguma consciência das causas da degradação e dos perigos que esta degradação pode causar em seu cotidiano. Esse conhecimento parece ter estimulado a problematização da questão ambiental e a necessidade de, materialmente, dispensarlhes cuidados.

O cuidado, através da proteção penal, para além de indicar a manutenção de um ambiente propício ao convívio e desenvolvimento das espécies animais, determina a proibição de atentados, buscando a não violação de um sentimento de altruísmo inerente ao padrão ético que ideologicamente se reforça pelo desvalor de um comportamento humano cruel. ${ }^{17}$

A motivação inicial de tutela ambiental foi eminentemente antropocêntrica e uti-

\footnotetext{
${ }^{16}$ SANTOS, Cleopas. Experimentação animal e direito penal. Curitiba: Juruá, 2015, p. 128.

17 Para Santiago Mir Puig, o desvalor da conduta se deve ao perigo para o bem jurídico que um espectador objetivo (o homem médio) pode observar na conduta no momento em que se realiza, ex ante. El desvalor de la conducta es, em este sentido, desva-
}

con los animales, pero en la consideración de que el animal como un ser sensible.

El análisis de los núcleos contenidos en el artículo 32 de la Ley de Delitos Ambientales requiere una comprensión de que el animal no es una cosa, ni un objeto de libre disposición, sino un ser vivo y sensible. Es necesario, por lo tanto, que el ser humano, reconozca un valor inherente a los seres de esta especie extendiéndolo así a la integridad del ideal de protección que tenía hasta ahora exclusivamente humano, en concreto, de no sufrir lesiones innecesarias. Cleopas Santos ${ }^{16}$ añade un argumento de naturaleza dogmática para mejorar la comprensión del nuevo postulado. El autor afirma que la agravación de la pena en el caso de muerte como consecuencia de maltrato o crueldad animal de experimentación (artículo 32, 2 de la Ley 9605) revela la preocupación del legislador acerca de la inutilidad de los resultados, sin duda, la comprensión que el derecho a la vida y la integridad física se encuentran asegurados a los animales.

\section{MOTIVOS DE LA PROTECCIÓN PENAL SOBRE} LA VIDA SILVESTRE

El creciente deterioro del medio ambiente natural pasó, desde hace algún tiempo, a ser fácilmente constatable, dejando de ser una simple advertencia apocalíptica y mauagorento, interfiriendo directamente en la calidad de vida de las personas. Incluso la población menos educada (y también la porción más consumista) tiene que tener un cierto conocimiento de las causas de la degradación y los peligros que esto puede causar en su vida diaria. Este conocimiento parece haber estimulado el cuestionamiento de los problemas ambientales y la necesidad material de cuidarlo.

El cuidado a través de la protección penal, además de indicar el mantenimiento

\footnotetext{
${ }^{16}$ SANTOS, Cleopas, Experimentação animal e direito penal. Curitiba: Juruá, 2015, p. 128, Brasil.
} 
litarista: cuidar daquilo que serve à pessoa humana para impedir que sua destruição ou degradação cause um desequilíbrio incapaz de ser suportado pela espécie. Nesse pensamento se incluem também os animais.

As palavras da Lei dos Crimes Ambientais despertam uma nova idéia que diz respeito a outra meta finalística a ser alcançada pela norma: a de que o uso feito dos animais seja orientado por uma boa ética. Na realização dessa meta, o direito ambiental serviu como mero instrumento de consecução deste outro fim, a exemplo do que ocorreu como as chamadas caudas orçamentárias que já serviram neste país para propósitos mais nobres. ${ }^{18}$

Observe-se, como reforço à hipótese proposta, que o ato de abuso a que se refere o artigo 32 pode coloca em risco a saúde, a vida ou a existência da espécie animal. Essa expressão, empregada pela primeira vez no direito brasileiro em 34, no Decreto 24.645/34, pretendia descrever uma das formas de cometer maus-tratos contra os animais. Como destaca Luciana Caetano da Silva, durante o período em que vigorou o decreto não houve autor que definisse essa modalidade de maus-tratos que, ademais, não equivalia à forma de exigência de trabalho excessivo do animal ou uso inadequado. Muitas décadas depois, o termo é reintroduzido no direito mantendo a mesma imprecisão de outrora, imprecisão esta que atenta contra o princípio da taxatividade, como destaca a mesma autora. ${ }^{19}$

Essa falta de consenso em torno do significado da expressão permite que se interprete

lor intersubjetivo ex ante. IN: MIR PUIG, Santiago. Derecho Penal. Parte General. Buenos Airres: B de F, 2015. p.166.

18 A lei orçamentária 4.242 de 1927 , no artigo $3^{\circ}$, ao tratar da despesa geral da República dispunha, dentre outras providências, sobre medidas reeducativas que deviam ser aplicadas aos menores de 18 anos.

19 SILVA, Luciana Caetano da. Fauna terrestre no direito penal. Belo Horizonte: Mandamentos, 2001. de un entorno propicio para la convivencia y el desarrollo de las especies animales, determina la prohibición de los ataques, en busca de la no violación de un sentimiento de altruismo inherente a normas éticas que ideológicamente se ve reforzada por inutilidad de un comportamiento humano cruel. ${ }^{17}$

La motivación inicial para la protección del medio ambiente fue eminentemente antropocéntrica y utilitario: cuidar lo que sirve a la persona humana para evitar que su destrucción o degradación provoque un desequilibrio que no puede ser soportado por la especie. Este pensamiento también incluye animales.

Las palabras de la Ley de Delitos Ambientales despiertan una nueva idea que se refiere a otra meta final a ser alcanzada por la norma: que el uso que se hace de los animales sea guiado por la ética. En la consecución de este objetivo, la ley del medio ambiente sirve como un mero instrumento para la obtención de este propósito, como ejemplo se tienen las llamadas colas presupuestarias que han servido a este país con fines más nobles. ${ }^{18}$

Hay que tener en cuenta, como refuerzo a la hipótesis propuesta, que el acto de abuso que se refiere el artículo 32 puede poner en peligro la salud, la vida o la existencia de la especie. Esta frase, utilizada por primera vez en la legislación brasileña en 34 del Decreto 24.645 / 34 , pretendía describir una de las

\footnotetext{
17 Para Santiago Mir Puig, o desvalor da conduta se deve ao perigo para o bem jurídico que um espectador objetivo (o homem médio) pode observar na conduta no momento em que se realiza, ex ante. "El desvalor de la conducta es, em este sentido, desvalor intersubjetivo ex ante." IN: MIR PUIG, Santiago. Derecho Penal. Parte General. Buenos Aires: B de F, 2015. p. 166.

18 "A lei orçamentária 4.242 de 1927 , no artigo $3^{\circ}$, ao tratar da despesa geral da República dispunha, dentre outras providências, sobre medidas reeducativas que deviam ser aplicadas aos menores de 18 anos."
} 
tal uso, como sendo aquele cuja reprovação se faz por uma compreensão dialética: em razão da qualidade da ação humana lesiva, mas considerando o resultado expresso pela dor e sofrimento observável no animal. $\mathrm{Ou}$ seja, pretende-se, para além de que o homem comporte-se de acordo com um modelo tal de conduta que não embarace ou envergonhe sua própria espécie ao se contemplar no outro, que a vida e o bem-estar dos animais sejam preservados. A ênfase da norma se faz, desta forma, no padrão de conduta desejado e na necessidade de evitação do dano ou perigo de dano que ela possa representar.

A lei 9605 orienta a um modelo de humanidade que se deseja, quem sabe, possa reinar sobre toda a terra, sem que, para isto, precise manipular a vida sem respeito e destruí-la. O tipo contido no parágrafo primeiro e que proíbe a realização de experiências dolorosas em animais, ainda que para fins científicos, comporta considerações da mesma ordem.

Há algum tempo, vem-se tomando conhecimento das experiências - cruéis e degradantes para a própria espécie humana - que são realizadas em seres vivos com vistas a gerar novas e mais eficientes respostas científicas para males da humanidade. É inegável que se tem conseguido controlar e vencer muitas enfermidades e que biotecnologia anuncia uma reengenharia da vida. (Se se proporcionará mais felicidade para a pessoa humana, não se sabe, porém).

Essas investigações, curiosamente, revelam outra face da dualidade da existência porque mesmo as atrocidades praticadas durante o nazismo nos campos de concentração possibilitaram um expressivo alargamento do conhecimento científico, sobretudo no que diz respeito à vida e morte dos tecidos. Depois da Segunda Guerra Mundial, principalmente, foram divulgadas algumas das mais cruéis experiências realizadas em seres humanos bem como as atrocidades cometidas pelos cientistas japoneses com os formas de cometer el maltrato de los animales. Como destaca Luciana Caetano da Silva, durante el período que duró el decreto ningún autor pudo definir este tipo de abuso, por otra parte, no era equivalente a la forma de requisito de trabajo excesivo animal o uso inadecuado. Muchas décadas después, el término se vuelve a introducir en el derecho manteniendo la misma imprecisión de antes, esta imprecisión que va en contra del principio de taxatividad, como se destaca por el mismo autor. ${ }^{19}$

Esta falta de consenso sobre el significado de la expresión permite que se interprete tal uso, como aquel cuya reprobación se hace falta se hace por una comprensión dialéctica: debido a la calidad de la acción humana perjudicial, pero teniendo en cuenta el resultado expresado, en el dolor y el sufrimiento observables en el animal. Es decir, se pretende que, más allá que el hombre se comporta de acuerdo a un modelo tal que la conducta no avergüence a su propia especie a la vista en el otro, que la vida y el bienestar de los animales se conservan. El énfasis de la norma se hace, de forma que el estándar de comportamiento deseado y en la necesidad de evitar los daños o peligro de daño que puede presentar.

La ley 9605 guía a un modelo de humanidad que desea, quién sabe, reinar sobre toda la tierra, sin que, por ello, sea necesario manejar la vida sin respeto y destruirla. El tipo en el primer párrafo que prohíbe la realización de experimentos dolorosos en animales, incluso para fines científicos, implica consideraciones del mismo orden.

Desde hace algún tiempo, se trata sobre el aprendizaje de la experiencia - cruel y degradante para la especie humana - que se llevan a cabo en los organismos vivos con el fin de generar nuevos y más eficientes respuestas científicas a los males de la humanidad. No

\footnotetext{
${ }^{19}$ SILVA, Luciana Caetano da. Fauna terrestre no direito penal. Belo Horizonte: Mandamentos, Brasil, 2001.
} 
seus prisioneiros de guerra na realização de ensaios científicos.

Muitos experimentos incluíam uma longa exposição do fígado a raio-x; retirada de parte do sangue do prisioneiro e posterior substituição com sangue de cavalo; infecção de mulheres (chinesas) com sífilis de forma que se descobrisse métodos de prevenir a doença. Em outros, prisioneiros tinham seus braços congelados para testar vários métodos de descongelamento, o que terminava por produzir uma necrose, fazendo a com que o membro soltasse do resto do corpo.

No que diz respeito aos animais, pune-se com pena privativa de liberdade, a ação de quem neles realiza experiência cruel, ainda que necessária, quando existirem recursos alternativos, conforme o multicitado parágrafo primeiro do artigo 32.

Trata-se de uma redação um tanto quanto escapista porque não se sabe exatamente como comprovar a crueldade de uma dada experiência, nem tão pouco, a existência de recursos alternativos. A própria admissibilidade da vivissecção, que consiste em operar animais vivos para estudos de fenômenos fisiológicos, levanta uma forte dúvida sobre o significado de crueldade. Autores admitem que, uma vez anestesiados, não haveria sofrimento, mas se se retirar órgãos e partes do corpo durante o procedimento, a dor, o padecimento, necessariamente se instalarão uma vez cessada o entorpecimento anestésico.

Não havendo como levar a cabo tais atividades sem sofrimento, ou o tipo constitui um enunciado sem significação prática ou, o que se deseja evitar não é exatamente uma ação em sua exterioridade, mas o sentimento e a ética que lhe orientam; o que se deseja impedir é que a manipulação sobre animais se faça sadicamente, como expressão do pior de nós mesmos.

Por isso mesmo, Roxin ${ }^{20}$ admite que, em tais casos, contrariando o princípio penal da

\footnotetext{
${ }^{20}$ GRECCO, Luis. Princípio da lesividade e crimes
} de perigo abstrato, ou algumas dúvidas diante de se puede negar que han logrado controlar y superar muchas enfermedades y la biotecnología anuncia una reingeniería de la vida (Se proporciona más felicidad a la persona humana aunque no se sabe por qué).

Estas investigaciones, curiosamente, revelan otra cara de la dualidad de la existencia porque incluso las atrocidades durante los campos de concentración nazis permitieron una expansión significativa del conocimiento científico, especialmente con respecto a la vida y la muerte de los tejidos. Después de la Segunda Guerra Mundial, principalmente se dieron a conocer algunos de los experimentos más crueles en los seres humanos y las atrocidades cometidas por los científicos japoneses con sus prisioneros de guerra en la realización de las pruebas científicas.

Muchos experimentos incluyen una larga exposición del hígado a la de rayos x; retirada de la sangre del prisionero y su sustitución con sangre de caballo; la infección de mujeres (chinas) con sífilis de manera que descubrieron métodos para prevenir la enfermedad. En otros casos, los presos tenían sus brazos congelados para probar diferentes métodos de descongelación, que terminó produciendo la necrosis, lo que hace que el miembro se desprenda del resto del cuerpo.

En lo que se refiere a los animales, se sanciona con pena privativa de libertad, la acción de quien realiza practicas crueles, incluso si es necesario, cuando existen recursos alternativos, como lo refiere las varias veces citado primer párrafo del artículo 32.

Este es un ensayo algo escapista porque no se sabe exactamente cómo demostrar la crueldad de una experiencia determinada, ni la existencia de recursos alternativos. La propia admisibilidad de la disecciones, para operar animales vivos para estudios de fenómenos fisiológicos, plantea una fuerte duda sobre el sentido de la crueldad. Los autores admiten que, una vez anestesiado, no habría sufrimiento, pero si se retira órganos y partes del cuerpo durante el procedimiento, el 
exclusiva tutela de bem jurídico, tem-se uma incriminação sem que este princípio seja atendido, conforme já referido. Não nega o autor, todavia que o sentimento de solidariedade para com certos animais superiores cause repulsa diante de atos de crueldade com animais e, por isto mesmo, acolhe esta exceção à ideia de bem jurídico.

\section{CONCLUSÃO}

A relação do ser humano com o meio ambiente, especialmente com os animais perpassa a análise de considerações que permeiam a ética e o direito. O ser humano, autoconstituído com a imagem e semelhança do divino, estabeleceu-se como ser dotado de uma dignidade que, tradicionalmente, fundamenta uma cultura que referencia o Direito. A importância atribuída à dignidade humana, no entanto, não é um limite ao reconhecimento do valor das formas de vida não humanas, que importantes em si, e ao ser humano, necessitam de proteção.

Fato inegável é que os vulneráveis sempre foram utilizados como instrumento para a investigação científica e que, destas investigações, usufruímos todos nós. Por vezes, constroem-se argumentos que justificam a morte e sofrimento de alguns, sacrificados pelo benefício de outros. Ocorre que parcela expressiva da humanidade - que ainda abate o boi e engorda frangos, porcos e carneiros em confinado compartimento de terceira classe - deseja que as investigações científicas sejam feitas de uma forma digna e que não venham a envergonhar os "senhores da terra".

O novo constitucionalismo latino americano e os movimentos ambientalistas e animalistas postulam o reconhecimento do animal como sujeito de direitos e sua preservação de atos atentatórios à integridade

tantas certezas. Revista Brasileira de Ciências Criminais. São Paulo: RT,n. 49. pp. 89-147. dolor, el sufrimiento, necesariamente va a instalarse una vez concluido el adormecedor anestésico.

Sin tener oportunidad de llevar a cabo dichas actividades sin sufrimiento, se perciben enunciados sin significancia práctica, lo que se pretende evitar no es exactamente una manifestación externa, lo que se pretende es generar un sentimiento ético que le oriente, a impedir que el manejo de los animales se realice de manera sádica como una expresión de lo peor de nosotros mismos.

Por lo tanto, Roxin ${ }^{20}$ acepta que, en tales casos, en contra del principio penal de la protección de los bienes jurídicos, que se está frente a una acusación sin que se cumpla este principio, como se ha mencionado. No niega el autor, sin embargo, que el sentimiento de solidaridad con ciertos animales superiores causa repulsión ante actos de crueldad animal y, por esta razón, da la bienvenida a esta excepción a la idea de bien jurídico.

\section{CONCLUSIÓN}

La relación entre los seres humanos y el medio ambiente, en especial con los animales, contempla el análisis de las consideraciones que subyacen a la ética y el derecho. El ser humano, auto constituido como la imagen y semejanza de Dios, se ha consolidado como ser dotado de una dignidad que tradicionalmente se funda en una cultura que hace referencia al derecho. El énfasis en la dignidad humana, sin embargo, no es un límite para el reconocimiento del valor de las formas no humanas de la vida que de por sí son importantes y merecen protección.

Un hecho innegable es que los vulnerables siempre han sido utilizados como una herramienta para la investigación científica y que de estas investigaciones, disfrutamos todos

${ }^{20}$ GRECCO, Luis. Princípio da lesividade e crimes de perigo abstrato, ou algumas dúvidas diante de tantas certezas. Revista Brasileira de Ciências Criminais. São Paulo: RT,n. 49. pp. 89-147, Brasil. 
e bem estar físicos, muitas vezes realizados para fins puramente supérfluos.

A verdade é a que a vida se alimenta de todos; diz-se, que o homem se alimenta de tudo que a terra produz até que, um dia, ela se alimente dele mesmo. Esta é, aliás, é a grande partilha, a verdadeira socialização da existência, o banquete, do qual todos participam. É preciso se empenhar na vivência de um perfil ideológico capaz de equilibrar as demandas desenvolvimentistas da sociedade contemporânea com a interação responsável e não hostil com o meio ambiente.

O Direito Penal, ainda que, secundaria e impropriamente, quer, com dispositivos como os comentados, dar a sua parcela de contribuição nesse processo, permitindo que o compartilhamento seja feito de forma equânime, evitando a dor desnecessária e cruel. nosotros. A veces se acumulan argumentos para justificar la muerte y el sufrimiento de algunos, sacrificado en beneficio de otros. Sucede que una porción de la humanidad - todavía sacrificar a los pollos de engorde de ganado y cerdos, ovejas y confinado compartimiento de tercera clase - quieren que la investigación científica que se hace de una manera digna y que no generen vergüenza a los señores de la tierra.

El nuevo constitucionalismo de movimientos de América Latina y ambientales postula el reconocimiento del animal como sujeto de derechos y la preservación de los ataques a la integridad y bienestar físico, lleva a cabo a menudo con fines puramente superfluos.

La verdad es que la vida se alimenta de todos; se dice que el hombre come todo lo que la tierra produce hasta que un día se alimenta a sí mismo. Esto es, por cierto, la gran división, la socialización real de la existencia, el banquete del cual, todos participan. Es preciso participar en la experiencia de un perfil ideológico capaz de equilibrar las necesidades de desarrollo de la sociedad contemporánea con la interacción no hostil responsable con el medio ambiente.

El derecho penal, a pesar que de manera secundaria e inapropiadamente pretenda generar dispositivos como los comentados, estos brindan una pequeña asistencia a este proceso, permitiendo que la contribución sea de forma ecuánime evitando así el dolor y la crueldad innecesaria. 
REFERÊNCIAS

BECK, Ulrich, Sociedade de Risco: Rumo a uma outra modernidade. Tradução: Sebastião Nascimento. São Paulo: Editora 34, Brasil, 2010.

BRASIL. Constituição Federal. Presidência da República, Casa Civil, Subchefia para Assuntos Jurídicos. Disponible en: http://www.planalto.gov.br/ccivil_03/constituicao/ constituicaocompilado.htm. Acesso em 29 de out de 2016.

CARVALHO NETO, Menelick, Notas de Aulas: curso de Hermenêutica Filosófica e Teoria da Interpretação, Mestrado em Direito, Faculdade de Direito da UFBA, Salvador, Brasil, 2000.

GOLDIM, José Roberto e Márcia Mocellin Raymundo, Pesquisa em Saúde e Direito dos Animais. 1999. www.ufrgs.br/HCPA/animrt.ht

GRECO, Luis, Princípio da lesividade e crimes de perigo abstrato, ou algumas dúvidas diante de tantas certezas. Revista Brasileira de Ciências Criminais. São Paulo: RT,n. 49. pp. 89-147, Brasil.

HASSEMER, Winfried, História das Idéias Penais na Alemanha de Pós-Guerra, Fundação Escola Superior do Ministério Público, Porto Alegre, Brasil, 1994.

HULSMAN, Louk. BERNAT DE CELIS, Jacqueline, Sistema Penal y Seguridad Ciudadana. Hacia uma alternativa. Ariel: Barcelona, 1984.

KOLLAKOWSKI . A Aldeia Incontrolável. Universidade de Brasília. Brasil, 1979.

MIR PUIG, Santiago, Bases Constitucionales del Derecho Penal, Iustel: Madrid, 2011.

, Derecho Penal. Parte General. Buenos Airres: B de F, 2015.

MONSALVE, Julio César Rodas, La proteccion Penal Del ambiente y Funcion Siombólica Del derecho Penal. In Derecho penal y Criminología, v. 15, n. 51, set/dez. 1993.

PRADO, Luis Regis, Crimes Contra o Ambiente, São Paulo: editora revista dos Tribunais, Brasil, 2001.

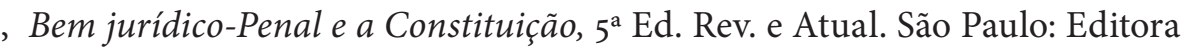
Revista dos Tribunais, Brasil, 2011.

PRIETO SANCHÍS, Luis, "La Filosofia Penal de la Ilustración”. In: História de los Derechos Fundamentales, Tomo II - Siglo XVIII, Vol. II - La Filosofia de los Derechos Humanos, PECES-BARBA MARTINEZ, Gregório et alii (directores). Madri: Dykinson, 2001.

RAYMUNDO, Márcia M e José Roberto Goldim. Diretrizes para Utilização de Animais em Experimentos Científicos. www.ufrgs.br/HCPA/gppg

SANTOS, Cleopas. Experimentação animal e direito penal. Curitiba: Juruá, Brasil, 2015.

SILVA SÁNCHES. Jesús-Maria. A Expansão do Direito Penal. Aspectos da política criminal nas sociedades pós-industriais. Revista dos Tribunais: São Paulo, Brasil, 2011. 
SILVA, Luciana Caetano da. Fauna terrestre no direito penal. Belo Horizonte: Mandamentos, Brasil, 2001.

SIRVINSKAS, Luís Paulo. Tutela penal do Meio Ambiente; breves considerações atinentes à lei 9605, São Paulo: Saraiva, Brasil, 1998.

STRATENWERTH. Günther. Derecho Penal. Parte General. I. El Hecho Punible. Fabian J. Di Placido: Buenos Aires, 1999.

WARAT, Luis Alberto. Por Quien Cantan Las Sirenas. UNOESC/CPGD-UFSC. Santa Catarina, Brasil, 1966.

WOLF, Paul. Magacriminalidad ecológica e derecho ambiental simbólico (una intervención iusfilosófica en el sistema de la organizada irresponsabilidad): Barcelona, 1990, ejemplar dactilografado.

ZAFFARONI, Eugenio Raúl. «La naturaleza como persona: Pachamama y Gaia». En Bolivia: Nueva Constitución Política del Estado. Conceptos elementales para su desarrollo normativo, 109-132. La Paz: Vicepresidencia del Estado Plurinacional de Bolivia, 2010.

ZUCCA, Aldo Jacomo. O direito da terra - rumo a um direito internacional ambiental efetivo. Rio de Janeiro: Qualitymark, Brasil, 1991. 